Proceedings of the 2013 Winter Simulation Conference

R. Pasupathy, S.-H. Kim, A. Tolk, R. Hill, and M. E. Kuhl, eds

\title{
CHALLENGES IN TEACHING MODELING AND SIMULATION ONLINE
}

\author{
Osman Balci \\ Kirby Deater-Deckard \\ Anderson Norton \\ Departments of Computer Science, Psychology, and Mathematics \\ Virginia Polytechnic Institute and State University (Virginia Tech) \\ Blacksburg, Virginia 24061, USA
}

\begin{abstract}
With the emergence of free Massive Open Online Courses (MOOCs), online education has been in the headlines in recent years. Many universities are offering online courses, some free and some for pay tied to a degree program. However, the lack of sufficient quality in existing online courses is undeniable. In particular, teaching Modeling and Simulation $(M \& S)$ as an undergraduate or graduate-level online course poses significant technical challenges for instructors. This paper presents an online learning quality model and discusses such challenges by giving the first author's own free online M\&S courseware as an example. The quality model presented provides guidelines for the development of any online course.
\end{abstract}

\section{INTRODUCTION}

Online learning, online course offerings, online degree programs, or online education is one of the fastest growing trends in educational uses of Internet-based technology. Online learning removes the traditional boundaries of time and location to offer the student the flexibility to conduct the learning activities according to his or her availability, anytime and anywhere. Online course materials are usually provided on the course website for access and use by the students enrolled in the course over the Internet, typically by using a web browser.

For example, students or anyone else can access the Modeling and Simulation (M\&S) courseware published online by Balci (2013). Using a web browser such as Google Chrome, Apple Safari, Microsoft Internet Explorer or Mozilla Firefox on an Internet-connected computer or mobile device, anyone can access and use this courseware from anywhere at anytime free of charge.

Advances in cloud computing and affordability of high-speed Internet connections at homes and schools have made it possible to provide online education to the masses. In recent years, private entities and elite universities such as Harvard, MIT, and Stanford have started offering free and Massive Open Online Courses (MOOCs). Lately, we have seen the emergence of startups, such as Udacity, Coursera and edX, which have offered hundreds of college-level courses online, free of charge, for millions of students worldwide. Many universities have started offering courses and even entire degree programs completely online. (Cusumano 2013, Ripley 2012)

College education is increasingly becoming more expensive every year. According to the Federal Reserve Bank of New York, Americans owe almost \$1 trillion in student loans (Ripley 2012). Steep rises in tuitions force students to look for free education, which is now becoming more and more possible with the availability of online courses and MOOCs. However, Cusumano (2013, p. 29) argues that "Elite universities need to ensure the true costs of their MOOCs do not become too high for society as a whole by destroying the economic foundations of less-prominent educational institutions — or of themselves." 


\section{Balci, Deater-Deckard, and Norton}

TIME magazine's special report on Reinventing College indicates that "There was just one problem: online classes were not, generally speaking, very good. To this day, most are dry, uninspired affairs, consisting of a patchwork of online readings, written Q\&As and low-budget lecture videos." (Ripley 2012, p. 35) It seems that under the hype of "free" and "massive", the quality is forgotten.

This paper presents a Quality Model for evaluating the quality of online learning and discusses the challenges in teaching M\&S online. A hierarchy of indicators is given in Section 2 for evaluating online learning quality. The challenges in teaching $M \& S$ online are discussed in Section 3. Concluding remarks are provided in Section 4.

\section{ONLINE LEARNING QUALITY MODEL}

Quality is a critically important issue in almost every discipline. "Quality is Job 1!" has become the motto. Whether we manufacture a product, employ processes or provide services, quality often becomes a major goal. Achieving that goal is the challenge. Many associations have been established worldwide for quality, e.g., American Society for Quality (http://www.asq.org), Australian Organization for Quality (http://www.aoq.asn.au), European Organization for Quality (http://www.eoq.org), and Society for Software Quality (http://www.ssq.org). Manufacturing companies have quality control departments, business and government organizations have Total Quality Management programs, and software development companies have Software Quality Assurance departments. (Balci 2004)

Anyone can teach or offer an online course. That is not the challenge! The challenge is to create the content of an online course with sufficient quality characteristics so as to enable the student to effectively self learn the subject matter. The ultimate goal is to provide the best possible quality for online learning.

Evaluation of the quality of online learning in an online course is a very complex process, involves the measurement and evaluation of dozens of qualitative and quantitative elements, mandates subject matter expert evaluation, and requires the integration of disparate evaluations. Planning and managing such measurements and evaluations require a unifying methodology and should not be performed in an ad hoc manner.

The first author has developed such a methodology and applied it for M\&S application certification (Balci 2001; Balci et al. 2002) and network-centric military system architecture assessment (Balci and Ormsby 2008). The methodology consists of the following body of methods, rules, and postulates:

a) employment of subject matter experts,

b) construction of a hierarchy of indicators,

c) relative criticality weighting of indicators using the analytic hierarchy process,

d) using a rule-based expert knowledge base with an object-oriented specification language,

e) assignment of crisp, fuzzy, and nominal scores for the indicators,

f) aggregation of indicator scores,

g) graphical representation of the indicator scores and weights,

h) hypertext certification report, and

i) interpretation of the results.

This methodology can also be applied for evaluating the quality of online learning. For use under this methodology, we present an Online Learning Quality Model as depicted in Figure 1.

A hierarchy of indicators is presented in Figure 1 for evaluating Online Learning Quality. These indicators make up the higher levels of the hierarchy and the quality model is not intended to be complete. The leaf indicators that cannot be assessed directly must be decomposed further into other indicators until all leaf indicators are directly assessable. The hierarchy of indicators is presented in the form of a tree structure for simplicity when in fact it should form an acyclic graph where a child indicator can have multiple parents, i.e., an indicator can influence more than one indicator in the hierarchy. 
Balci, Deater-Deckard, and Norton

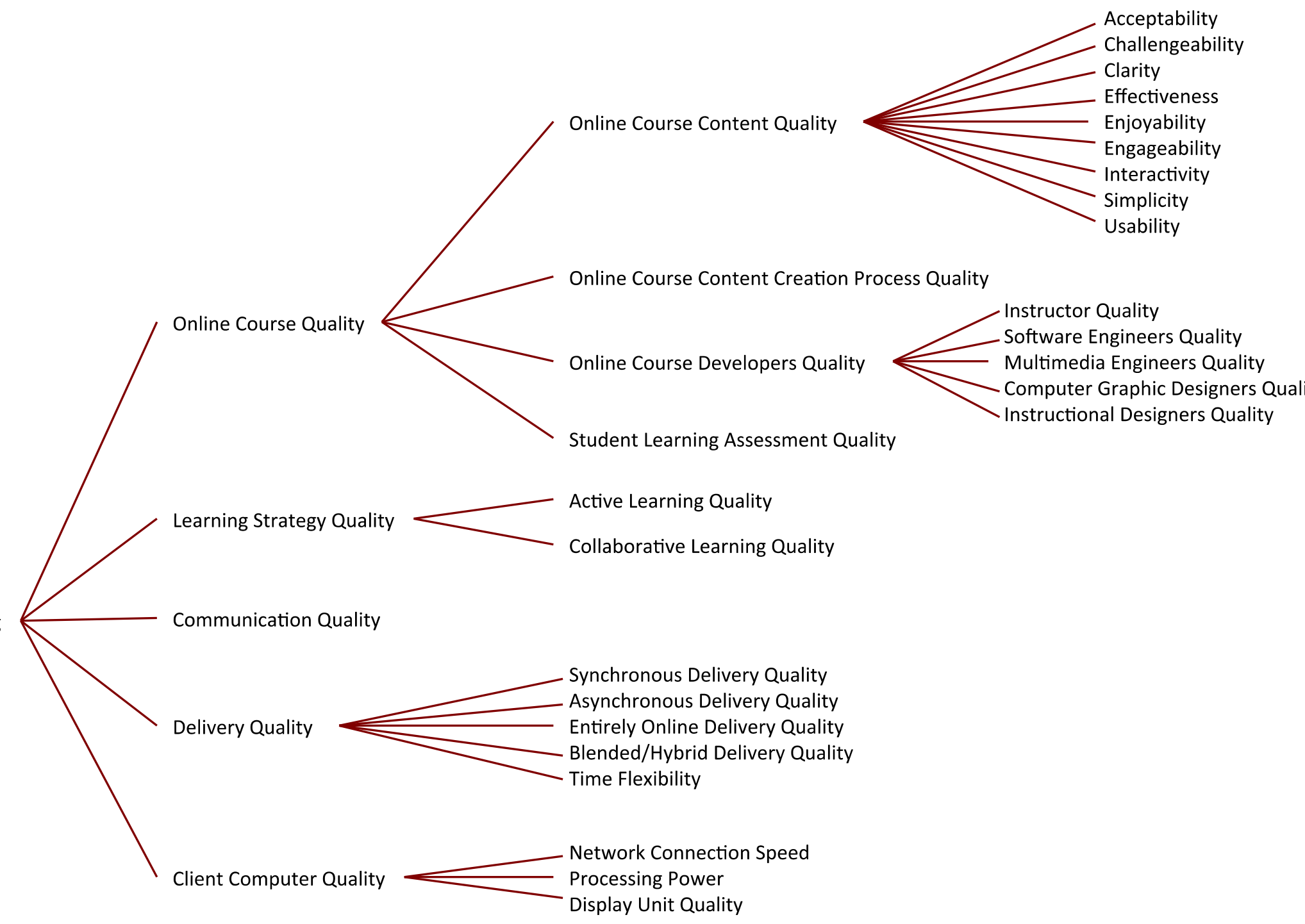

Figure 1: Online Learning Quality Model 
Online Learning Quality is the degree to which the online learning possesses a desired set of characteristics. As depicted in Figure 1, Online Learning Quality is evaluated by using the following five toplevel indicators:

- Online Course Quality is the degree to which the online course possesses a desired set of characteristics.

- Learning Strategy Quality is the degree to which the pedagogy used in the online course possesses a desired set of characteristics.

- Communication Quality is the degree to which the online course students can easily get in touch and interact with the course instructor.

- Delivery Quality is the degree to which the online course is accessed by geographically dispersed students anywhere and anytime by using a networked computer or a mobile device.

- Client Computer Quality is the degree to which the networked computer (e.g., desktop, laptop) or a hand-held computer / mobile device (e.g., iPad, iPod Touch, iPhone, Android tablet or phone, Windows tablet or phone) used by the online course student provides acceptable performance in accessing and using the online course content.

Online Course Quality is evaluated by using the following indicators:

- Online Course Content Quality is the degree to which the online course content possesses a desired set of characteristics. These characteristics should address not only the products of experts in the field, but also the processes in which those experts engage. For example, content related to mathematics might include theorems that mathematicians haven proven, but should also include the processes of conjecturing and proving by which those products arise (NCTM 2000). This way, online courses become more than training grounds for disseminating knowledge about existing facts, procedures, classifications, and algorithms; they support the development of new experts in the field.

- Online Course Content Creation Process Quality is the degree to which the online course content creation process is based on structured and effective instructional design activities under clearly articulated learning objectives, software and multimedia engineering best practices, and creation of designs and illustrations using principles of art. These learning objectives should be based on available research on learning progressions so that the objectives identify critical benchmarks for developing expertise, and so that the curriculum can specify educational tasks that support educational progress. Building on the previous example, research in undergraduate mathematics education (e.g., Harel and Sowder 2005) has identified a trajectory by which students progress from an impoverished understanding of proof (e.g., judging the validity of a conjecture based on a single example) toward a more sophisticated understanding (e.g., building a formal proof from informal, but logical, arguments).

- Online Course Developers Quality is the degree to which the online course developers possess the required knowledge and skills.

- Student Learning Assessment Quality is the degree to which student's capabilities, progress, and academic outcome are properly measured by using formative and summative assessment techniques. Whereas summative assessments provide valuable information for instructors in determining whether students have met learning objectives, ongoing formative assessment is critical to supporting students' progress toward those objectives. This is a key challenge for online instruction because, for instruction to be effective, it must be informed by students' current ways of thinking. Yet instructors of online courses do not have the benefit of personal contact in making these formative assessments about how students are approaching learning objectives. 


\section{Balci, Deater-Deckard, and Norton}

Online Course Content Quality is evaluated by using the following indicators:

- Acceptability is the degree to which the online course content fulfills its requirements and learning objectives.

- Challengeability is the degree to which the learner finds the online course content to be exciting, stimulating, and inspiring.

- Clarity is the degree to which the online course content is unambiguous and understandable.

- Effectiveness is the degree to which the online course content improves the effectiveness of learning the subject matter in a significantly better way in comparison to other pedagogies.

- Enjoyability is the degree to which the learner finds the online course content to be fun to interact with.

- Engageability is the degree to which the learner is captivated and addicted by using the online course content.

- Interactivity is the degree to which the learner actively interacts with the online course content during learning activities.

- Simplicity is the degree to which the online course content can be understood without difficulty.

- Usability is the degree to which the online course content can easily be employed for its intended use.

Online Course Developers Quality is evaluated by using the following indicators:

- Instructor Quality is the degree to which the instructor of the online course possesses expertise and teaching skills about the subject matter being taught online.

- Software Engineers Quality is the degree to which the web-based software engineers, netcentric software engineers, and usability engineers employed for the development of the online course content possess the required expertise and skills.

- Multimedia Engineers Quality is the degree to which the multimedia engineers employed for the development of the online course content possess the expertise required for creating digital videos, audios, animations, still images, and interactivity.

- Computer Graphic Designers Quality is the degree to which the graphic designers possess the expertise required for creating designs and illustrations under the principles of art for the online course content.

- Instructional Designers Quality is the degree to which the instructional designers employed for the development of the online course possess the expertise required for creating online instructional experiences which enable the students to acquire the knowledge and skill in a more efficient, effective, and appealing manner (Wikipedia 2013).

Learning Strategy Quality is evaluated by using the following indicators:

- Active learning Quality is the degree to which the learner can build knowledge through inquiry-based manipulation of digital artifacts such as online exercises, animations, simulations, games, or learning environments (Means et al. 2010).

- Collaborative Learning Quality is the degree to which the learner can build knowledge through inquiry-based collaborative interaction with other learners, where teachers become co-learners and act as facilitators (Means et al. 2010). 


\section{Balci, Deater-Deckard, and Norton}

Delivery Quality is evaluated by using the following indicators:

- Synchronous Delivery Quality is the degree to which the online learning activity occurs concurrently with the instruction in real time in a physical or a virtual environment.

- Asynchronous Delivery Quality is the degree to which the online learning activity occurs with a time lag between the presentation of instructional stimuli and student responses.

- Entirely Online Delivery Quality is the degree to which the entire course is taught online as an alternative to face-to-face teaching.

- Blended/Hybrid Delivery Quality is the degree to which online learning components are combined or blended (a.k.a. hybrid or flipped) with face-to-face instruction to provide learning enhancement.

- $\quad$ Time Flexibility is the degree to which the student can spend the time for learning according to his or her availability, anytime and anywhere.

Client Computer Quality is evaluated by using the following indicators:

- Network Connection Speed is typically measured by gigabit per second (Gbps) or megabit per second (Mbps) for a wired or wireless network to which the student's client computer or mobile device is connected.

- Processing Power refers to the powerfulness of the central processing unit (CPU) of the student's client computer or mobile device.

- Display Unit Quality is the degree to which the student's client computer or mobile device provides a screen with high resolution and acceptable performance.

\section{CHALLENGES IN TEACHING M\&S ONLINE}

Creating an M\&S online course to enable online learning with sufficient quality in accordance with the quality model presented in section 2 poses significant challenges not only for instructors, but also for educational institutions.

The biggest challenge is the creation of the online course content with sufficient quality as measured by the indicators shown in Figure 1. Creation of high quality online course content requires expertise in:

(1) the M\&S topics being taught online, and

(2) engineering a web-based interactive multimedia software system to contain and deliver the online course content.

Requirement 1 above is satisfied by the course instructor who must be an expert in the M\&S topics being taught. Requirement 2 above is satisfied by:

- Software Engineers (e.g., web-based software engineers, net-centric software engineers, usability engineers),

- Multimedia Engineers (who create digital videos, audios, animations, still images, and interactivity to enable students to learn better),

- Computer Graphic Designers (who create designs and illustrations under the principles of art to enable students to learn better), and

- Instructional Designers (who create online instructional experiences which make the acquisition of knowledge and skill more efficient, effective, and appealing.)

Teaching an online course cannot be effectively accomplished by just the instructor who typically does not possess the expertise under requirement 2 above. An instructor, a classroom, and blackboard or whiteboard or audio/visual equipment have been traditionally sufficient for face-to-face instruction. However, online courses cannot be offered with the traditional resources and it becomes a serious challenge 


\section{Balci, Deater-Deckard, and Norton}

for educational institutions to satisfy the new information technology (IT) requirements created by online education. Universities must now establish an IT branch to provide the expertise under requirement 2 above and help the faculty develop and teach online courses.

To teach a high-quality online course, instructors must re-develop the course for the online environment. Traditional courseware created for face-to-face instruction is definitely not sufficient to teach the same course online. For example, the first author's M\&S courseware (Balci 2013) was created for faceto-face instruction and therefore, it is not sufficient to teach a high-quality M\&S online course. The course slides are intended to provide talking points for the instructor. Monologues delivered by an instructor in a recorded video are known to be boring and alienating for the students.

In face-to-face instruction, a "sense of belonging" and a "sense of community" develops naturally as a result of face-to-face interactions among the students and the instructor. Creating such senses poses significant challenges in an online course.

One of the advantages of online learning is that the student has the flexibility to conduct the learning activities according to his or her availability. However, this becomes a disadvantage for those students who are challenged by time management. Effective time management, self-motivation, and discipline are requirements for becoming successful in an online course. A widely quoted dropout rate for students in MOOCs is about $90 \%$, which may be attributed to the lack of these requirements.

Enforcing academic integrity in an online course remains to be a serious challenge. The inability to control a student's environment while taking an online exam has been a major challenge for educational institutions. Cheating in an online exam occurs in many forms including (a) someone else taking the online exam in place of the registered student, (b) receiving assistance from others during an online exam, and (c) accessing materials that are not allowed. (Rodchua, Yiadom-Boakye, and Woolsey 2011)

\section{CONCLUDING REMARKS}

Many universities have been rushing to provide online education to make money. During this rush, quality and academic integrity are forgotten. Universities should overcome the challenges presented in this paper and offer their online courses with high quality and academic integrity for tuition paying students.

Creation of high quality online courses is an onerous task requiring millions of dollars of investment for academic institutions. Development of a high-quality online degree program for tuition paying students requires a structured process, strong leadership, incentives for the faculty, and IT support for online course content creation and should not be performed in an ad hoc manner.

For research-oriented faculty, online teaching is considered as a burden since it does not usually contribute to research and recruitment of graduate research assistants. University leaders should identify incentives to motivate research faculty to teach high-quality online courses.

\section{REFERENCES}

Balci, O. 2001. "A Methodology for Certification of Modeling and Simulation Applications." $A C M$ Transactions on Modeling and Computer Simulation (TOMACS) 11, 4 (Oct.):352-377.

Balci, O. 2004. "Quality Assessment, Verification, and Validation of Modeling and Simulation Applications," In Proceedings of the 2004 Winter Simulation Conference (Washington, DC, Dec. 5-8). IEEE, Piscataway, NJ, pp. 122-129.

Balci, O. 2013. "Online M\&S Courseware: Introduction to Modeling and Simulation." ACM SIGSIM M\&S Knowledge Repository, http://www.acm-sigsim-mskr.org/Courseware/Balci/introToMS.htm

Balci, O., R. J. Adams, D. S. Myers, and R. E. Nance. 2002. "A Collaborative Evaluation Environment for Credibility Assessment of Modeling and Simulation Applications." In Proceedings of the 2002 Winter Simulation Conference (San Diego, CA, Dec. 8-11). IEEE, Piscataway, NJ, pp. 214-220.

Balci, O. and W. F. Ormsby. 2008. "Network-Centric Military System Architecture Assessment Methodology." International Journal of System of Systems Engineering 1, 1-2:271-292. 
Cusumano, M. A. 2013. "Are the Costs of 'Free' Too High in Online Education?" Communications of the ACM 56(4): 26-28.

Harel, G. and L. Sowder. 2005. "Advanced Mathematical-Thinking at any Age: Its Nature and its Development." Mathematical Thinking and Learning 7, 1: 27-50.

Means, B., Y. Toyama, R. Murphy, M. Bakia, and K. Jones. 2010. "Evaluation of Evidence-Based Practices in Online Learning: A Meta-Analysis and Review of Online Learning Studies." U.S. Department of Education, Washington, D.C.

NCTM. 2000. "Principles and Standards for School Mathematics." National Council of Teachers of Mathematics (NCTM), Reston, VA.

Ripley, A. 2012. "Reinventing Higher Education: College is Dead. Long Live College!" TIME Magazine, Vol. 180, No. 18, Oct. 29, pp. 31-41. http://nation.time.com/2012/10/18/college-is-dead-long-livecollege/

Rodchua, S., G. Yiadom-Boakye, and R. Woolsey. 2011. "Student Verification System for Online Assessments: Bolstering Quality and Integrity of Distance Learning." Journal of Industrial Technology 27, 3:1-8.

Wikipedia. 2013. “Instructional Design.” http://en.wikipedia.org/wiki/Instructional_design

\section{AUTHOR BIOGRAPHIES}

Osman Balci is Professor of Computer Science and Director of the Mobile Software Engineering Lab at Virginia Tech. He received his Ph.D. degree from Syracuse University in 1981. Dr. Balci served as the Editor-in-Chief of two international journals: Annals of Software Engineering, 1993-2002 and World Wide Web, 1996-2000. He served as Chair of ACM SIGSIM, 20082010; and Director at Large of the Society for M\&S International, 2002-2006. Most of Dr. Balci's work has been funded by the U.S. Navy since 1983. His current areas of expertise center on Software Engineering (iOS mobile SE, net-centric SE, IV\&V), architecting system of systems, M\&S (methodology, V\&V, certification), and Digital Game-Based Learning. His e-mail andweb addresses are balci@vt.edu and http://manta.cs.vt.edu/balci.

KIRBY DeATER-DECKARD is Professor and Director of the Developmental Science program in Psychology at Virginia Tech, Professor of Psychiatry at Virginia Tech - Carilion School of Medicine, and Director of Virginia Tech Community Partners in Roanoke, Virginia. He received his Ph.D. degree in Psychology from the University of Virginia in 1994. Dr. Deater-Deckard served as Joint Editor of the international Journal of Child Psychology and Psychiatry, and his work has been funded by the National Science Foundation and National Institutes of Health. Current research foci include work on the causes and consequences of individual differences in engagement and learning in children and adolescents. His e-mail and web addresses are kirbydd@vt.edu and http://www.psyc.vt.edu/users/kirbydd.

Anderson NorTon is Associate Professor of Mathematics at Virginia Tech. He received his Ph.D. in Mathematics Education from the University of Georgia in 2004. Dr. Norton was the 2013 recipient of the Early Career Research Award from the Association of Mathematics Teacher Educators and currently serves as the editorial panel chair for the Journal of Research in Mathematics Education. Dr. Norton's research focuses on building models of students' mathematical knowledge and learning. His email and web addresses are norton3@vt.edu and http://www.mathed.soe.vt.edu/Faculty/norton.html. 